\title{
Quick Method for Determination of Fructose-Glucose Ratio in Agave Syrup
}

\author{
Mejia-Barajas $\mathrm{JA}^{1}$, Molinero-Ortiz $\mathrm{E}^{1}$ and Sosa-Aguirre $\mathrm{CR}^{2 *}$
}

${ }^{1}$ Centro de Innovacion y Desarrollo Agroalimentario de Michoacan AC, Mexico

${ }^{2}$ Universidad Michoacana de San Nicolas de Hidalgo, Instituto de Investigaciones Quimico Biologicas, Mexico

\begin{abstract}
Fructose is $30 \%$ sweeter than sucrose, the sweetest natural sugar in the world and the main compound of agave syrup. Although fructose can be got from different syrups through a chromatographic system, the methods to evaluate their purification are expensive and too long time. In this work, using a polarimetric method was determinate the fructose-glucose ratio from agave syrup before and after their process by a chromatography method. The polarimetric method was validated using a standard HPLCbased method. With the results of this work was development a rapid and economic technique to determinate the fructose-glucose ration in agave syrup.
\end{abstract}

Keywords: Agave syrup; Fructose; Glucose; Polarimetric; HPLC

\section{Introduction}

The fructose is used as a dietary sugar in an increasing variety of products of industrial relevance. Since fructose does not require insulin in its metabolic pathway, fructose-based foods may be helpful in diabetic's diets and to control blood-sugar levels [1]. Fructose can be produced by acid or enzymatic hydrolysis of sucrose or through their purification from corn and agave syrups, due this sugar is their main compound. The agave syrup which is a natural sweetener considered sweeter than honey, is used as sugar substitutes, and it is produced when different agave species pines are cooked [2]. The agave syrup with high quality fructose is clear in color, without aroma agave plant, and had been reported with antioxidant [3] and antibacterial properties [4]. Although fructose is found between $70 \%$ to $90 \%$ in agave syrup, a higher purity is necessary to have fructose crystal, due the presence of glucose inhibited fructose crystallization. Even though the fructose and glucose separation can be achieved by methods as chromatography, cooling crystallization, and reverse osmosis [5]; the evaluation of their separation by high performance liquid chromatography (HPLC), gas chromatography-mass spectrometry (GC-MS), or nuclear magnetic resonance (NMR) [6,7], is expensive and delaying. For the last, the aim of this work was the development of an inexpensive and quick method to measure fructose-glucose ratio from agave syrup before and after a chromatography process.

\section{Materials and Methods}

\section{Agave syrup}

Were used three different agave syrups samples, classified as sample $\mathrm{a}, \mathrm{b}$ and $\mathrm{c}$. All the agave syrups used in the present work were blue agave (Agave tequilana) derived.

\section{Chemicals}

Pure fructose and glucose were purchased from Sigma, México. Standard solutions of the sugars to be used as external reference for the HPLC method were prepared as described by Bogdanov et al. [8]. To sugars solution filtration Whatman filters of $25 \mu$ pore size were used.

\section{Chromatography process}

At the chromatography process was submitted the agave syrup sample 3. The chromatography equipment included four columns connected in series, feed pump, and eluent water pump. The height of each column was $1.0 \mathrm{~m}$ and each column had a diameter of $0.02 \mathrm{~m}$. The columns were packed with a strong acid gel type cation exchange resin (manufactured by DOWEX) in $\mathrm{Ca}^{2+}$ form, with the commercial name
DOWEX MONOSPHERE $99 \mathrm{Ca}^{2+} / 320$ resin. The water flow rate used was of $2.8 \mathrm{Lt} / \mathrm{h}$

\section{Polarimetric lectures}

Polarimetric standard curves were done using fructose-glucose solutions of know concentration. The calibration curves were done with $75 \%$ to $100 \%$ of fructose, at $10,25,30$ and $40^{\circ} \mathrm{Brix}$. The polarimetric lectures of the agave syrups samples and the fractions recollected after submitted one agave syrup to a chromatography process were done with the ADS420 Automatic Digital Saccharimeter. The Brix of the agave syrup chromatography processed were adjusted before their lectures.

\section{High performance liquid chromatography (HPLC) lectures}

Fructose and glucose standard solutions were prepared as described Bogdanov et al. [8]. These standard solutions were used as external reference for the HPLC lectures. The sugar solutions were prepared at $0,25,50$, and $100^{\circ}$ Brix. The sugars determination through HPLC is described in detail by Bogdanov et al. [8]. The sugars concentrations were analyzed with a Differential Refractometer Waters 410. Separation was achieved on a Phenomenex RNM-Carbohydrate $\mathrm{Na}^{+}$column $(300$ $\mathrm{mm} \times 7.8 \mathrm{~mm}$ ). Column temperature was maintained at $80^{\circ} \mathrm{C}$ with a heater (Eppendorf $\mathrm{CH}-30$ ). The mobile phase consisted of deionized water that was run at $0.20 \mathrm{~mL} / \mathrm{min}$.

\section{Statistics}

Each experiment and analyses were replicated thrice. To compare reproducibility and accuracy of the results got from polarity and HPLC, the Anova variancy (ANOVA) statistical tools was used.

\section{Results}

Polarimetric lectures of standard fructose-glucose solutions

Table 1 shows the results of polarimetric lectures $\left({ }^{\circ} \mathrm{Z}\right)$ of standard

*Corresponding author: Carlos R Sosa-Aguirre, Universidad Michoacana de San Nicolas de Hidalgo, Mexico, Tel: +52-4433265788; E-mail: csosa@biofermich.com

Received December 07, 2017; Accepted December 28, 2017; Published January 04, 2018

Citation: Mejia-Barajas JA, Molinero-Ortiz E, Sosa-Aguirre CR (2018) Quick Method for Determination of Fructose-Glucose Ratio in Agave Syrup. J Food Process Technol 9: 710. doi: 10.4172/2157-7110.1000710

Copyright: () 2018 Mejia J, et al. This is an open-access article distributed under the terms of the Creative Commons Attribution License, which permits unrestricted use, distribution, and reproduction in any medium, provided the original author and source are credited. 


\begin{tabular}{|c|c|c|c|c|c|}
\hline \multicolumn{3}{|c|}{$\%$} & \multicolumn{4}{|c|}{${ }^{\circ}$ Brix (g/Lt) } \\
\hline Fructose & Glucose & $\mathbf{1 0}$ & $\mathbf{2 5}$ & $\mathbf{3 0}$ & $\mathbf{4 0}$ \\
\hline 90 & 10 & -44.4 & -146.68 & -177.82 & -257.07 \\
\hline 85 & 15 & -39.33 & -125.05 & -150.54 & -219.45 \\
\hline 80 & 20 & -34.21 & -113.74 & -137.67 & -196.9 \\
\hline 75 & 25 & -28.75 & -102.48 & -123.67 & -176.65 \\
\hline
\end{tabular}

*The data are the results of three separate experiments.

Table 1: Polarimetric lectures $\left({ }^{\circ} \mathrm{Z}\right)$ of fructose-glucose standard solutions at different fructose-glucose proportions and Brix (g/L).

\begin{tabular}{|c|c|c|}
\hline${ }^{\circ}$ Brix (g/L) & Fructose & Glucose \\
\hline 0 & 0 & 0 \\
\hline 25 & 902.50 & 872.51 \\
\hline 50 & 1784.33 & 1760.03 \\
\hline 100 & 3559.90 & 3569.12 \\
\hline \multicolumn{2}{|c|}{} \\
\hline
\end{tabular}

Table 2: Content of fructose and glucose standards solutions determined by HPLC.

\begin{tabular}{|c|c|c|c|c|c|}
\hline \multirow{2}{*}{ Samples } & \multirow{2}{*}{${ }^{\circ}$ Brix (g/Lt) } & \multicolumn{2}{|c|}{ Polarimetric (\%) } & \multicolumn{2}{|c|}{ HPLC (\%) } \\
\cline { 3 - 6 } & & Fructose & Glucose & Fructose & Glucose \\
\hline a & 25 & 86.43 & 13.57 & 86.96 & 13.04 \\
\hline a & 30 & 86.98 & 13.02 & 86.64 & 13.36 \\
\hline a & 40 & 86.34 & 13.66 & 86.73 & 13.27 \\
\hline b & 25 & 83.31 & 16.69 & 85.91 & 14.09 \\
\hline b & 30 & 84.61 & 15.39 & 86.75 & 13.25 \\
\hline b & 40 & 83.93 & 16.07 & 84.62 & 15.38 \\
\hline c & 25 & 81.82 & 18.18 & 78.28 & 21.72 \\
\hline c & 30 & 82.01 & 17.99 & 77.96 & 22.04 \\
\hline c & 40 & 81.67 & 18.33 & 79.03 & 20.97 \\
\hline FAC1 & 10 & 87.98 & 12.02 & 81.11 & 18.89 \\
\hline FAC2 & 10 & 89.31 & 10.69 & 85.06 & 14.94 \\
\hline FAC3 & 10 & 87.55 & 12.45 & 86.86 & 13.14 \\
\hline FAC4 & 10 & 95.27 & 4.73 & 89.17 & 10.83 \\
\hline FAC5 & 10 & 95.92 & 4.08 & 89.86 & 10.14 \\
\hline FAC6 & 10 & 92.80 & 7.20 & 90.47 & 9.53 \\
\hline
\end{tabular}

The $\%$ of fructose-glucose was calculated according to the polarimetric and HPLC lectures of the standard fructose-glucose solutions. The ${ }^{\circ} \mathrm{Brix}$ of the agave syrup fractions and their ${ }^{\circ} Z$ values were interpolated into the reference curves. Data obtained for a specific experimental condition are the results of three separate batch experiments, and provided as mean.

Table 3: Percentage of fructose-glucose proportions of agave syrups samples determined by a polarimetric and HPLC method.

\begin{tabular}{|c|c|c|c|c|c|c|}
\hline $\begin{array}{c}\text { Origin of } \\
\text { variation }\end{array}$ & $\begin{array}{c}\text { Sum of } \\
\text { squares }\end{array}$ & $\begin{array}{c}\text { Degrees } \\
\text { of } \\
\text { freedom }\end{array}$ & $\begin{array}{c}\text { Average } \\
\text { of } \\
\text { squares }\end{array}$ & F & Probability & $\begin{array}{c}\text { Critical } \\
\text { value } \\
\text { for F }\end{array}$ \\
\hline Between groups & 130.12 & 1 & 130.12 & 1.4 & 0.23 & 4.13 \\
\hline Within the groups & 3092.60 & 34 & 90.95 & - & - & - \\
\hline Total & 3222.72 & 35 & - & - & - & - \\
\hline
\end{tabular}

Table 4: Anova variance analysis of the results of fructose-glucose proportions of agave syrups samples determined by a polarimetric and HPLC method.

fructose-glucose solutions. The solutions were prepared with a higher fructose proportion and with 10 to $40^{\circ} \mathrm{Brix}$, as mentioned in material and methods. The ${ }^{\circ} \mathrm{Z}$ showed an inversely proportional relation with the concentration of fructose and ${ }^{\circ} \mathrm{Brix}$.

\section{HPLC lectures of standard fructose-glucose solutions}

In the Table 2 are show the results of the HPLC lectures of standard fructose-glucose solutions. As is mentioned in material and methods, every standard sugar was evaluated separately. The results show areas under the curve got from the chromatography of every sugar. The areas under the curve were determinate with the program Chromulan 20002002. According with the conditions used in the HPLC, the fructose and glucose were retained at 20 and $30 \mathrm{~min}$, respectively.

\section{Polarimetric and HPLC lectures of the agave syrups samples before and after a chromatography process}

In the Table 3 is shows the fructose-glucose ratio of three agave syrups samples ( $a, b$, and $c)$, determinate through polarimetric and HPLC method. The results of the fractions after a chromatography (FAC) process are show in this table (Table 3 ). In the polarimetric methods the fructose was found to range between $81.67 \%$ to $95.92 \%$, while in the HPLC lectures ranged between $77.96 \%$ to $90.47 \%$. Most of the differences in the fructose percentage of the samples evaluated were less than 2. The FAC showed higher differences between the polarimetric and HPCL lectures; the highest difference was of $6.87 \%$ generated by the agave syrup fraction after chromatography (FAC).

\section{Statistics analysis of the polarimetric and HPLC results}

The Anova variance analysis performed to the results showed in the Table 3, determined that there are no statistically significant differences between the results got through polarimetric and HPLC method, since the $\mathrm{F}$ test value does not exceed the critical F value (Table 4).

\section{Discussion}

The fructose is a saccharide with commercial potential owing this is sweeter than glucose, and extensively used in food, pharmaceutical, and chemical industries [9]. Fructose is found in natural sources but in relatively low concentrations, therefore, their commercial quantities are manufactured from sucrose or polysaccharides. Sucrose enzyme-based inversion or acid method fructose production are more expensive than their purification from syrups, due this sugar is the main compound of syrups. A number of methods for fructose identification and their quality evaluation have been established [10], however, these methods are time-consuming and expensive. The fructose can be produced hydrolyzing inulin, whereby, inulinases are used to produce agave syrups from agave inulin [11]. The main sugars of agave syrup are fructose $(80 \%)$ and glucose (10\%), with lower levels of sucrose, mannitol and inositol, therefore, agave syrup is a fructose rich source with potential to fructose purification [12]. Although many analyses of fructose corn syrup have been conducted [13], relatively little information exists about fructose agave syrup. For the last and due fructose-glucose ratio could give indications of agave syrup factory process problems, development of a rapid and economic fructose-glucose agave syrup detection technique will be of practical significance. In this work is proposed the use of an easy, quick, and low cost polarimetric technique to evaluated fructose-glucose ratio from agave syrup.

To include a range of fructose concentrations, three commercial agave syrups were used (material and methods). One agave syrup sample was submitted to a chromatography process, getting six fractions that were evaluated as the original sample (Table 3). Although fructose is the main compound in agave syrups, due glucose has similar structure with fructose, their separation is a complicated process. The chromatography is a technique used to separated and identify fructose and glucose from corn syrup; especially cation exchange chromatography is considered a good option for fructose-glucose separation [14]. Previous work has used the cation exchange resins Dowex Monosphere 99/Ca, Dowex 50WX8, Amberlite CR1320Ca, and Diaion UBK 530, to separate fructose from glucose, and Ya-Jun et al. [15] developed a chromatographic process for fructose separation from high-fructose corn syrup using $\mathrm{Ca}^{2+-}$ immobilized cation exchanger XA 
2004/22. In this work was used an acid gel type cation exchange resin in $\mathrm{Ca}^{2+}$ form, commercial named Dowex MONOSPHERE $99 \mathrm{Ca}^{2+/ 320}$. The resin selection was conducted based on the adsorption capability of fructose, due the gel-type cation exchange resin in $\mathrm{Ca}^{2+}$ make strong complexes with fructose rather than glucose. The amount of the agave syrups samples with different Brix and the agave syrups samples after the chromatography process, generated a total of 15 samples, which were analyzed through HPLC and the polarimetric method here proposed (Table 3). For agave syrups exist the Mexican Standard NMXFF-110-SCFI-2008 that gives the general compositional guidelines for it. These standard lays parameters minimum value for soluble solids, maximum levels for hydroxylmethylfurfural, and fructose, glucose, and sucrose concentration. The syrup preferably should have a high fructose concentration ( $>90 \%$ ), with the remainder of the syrup comprising glucose, other saccharides, and trace minerals. Ours results indicate that all the agave syrups used satisfy the fructose concentration to be syrup. Although the fructose content varied among the samples tested, the methods here used (polarimetric and HPLC) showed similarity, therefore, fructose-glucose ratio determination can be obtained independent of the agave syrups brands (Table 3 ). The polarimetric method was validated by standard HPLC method (Table 3 ). To realize the HPCL analysis were used aqueous standards of glucose and fructose (Table 2). In the analysis of the agave syrup samples we found a mean fructose concentration of $83.93 \%$ and $85.91 \%$ by polarimetric and HPLC methods, respectively. To us know, this is the first study to determinate by a polarimetric method, the fructose-glucose ratio from agave syrup. To compare the two methods reproducibility and accuracy, the Anova statistical tools were used. In the measurements, the F test value (1.4) does not exceed the critical F value (4.13) (Table 4). Thus, the two methods (HPLC and polarimetric) are statistically equivalent in terms of accuracy and reproducibility, therefore, the technical feasibility of the method here proposed was demonstrated. Cabañero et al. [16] developed a new procedure for the determination of $13 \mathrm{C}$ isotope ratios of individual sugars using a combination of liquid chromatography and isotope ratio mass spectrometry (HPLC-IRMS), while RuizMatute et al. [17] studied the sugar composition of high-fructose corn syrup using gas chromatography coupled with mass spectrometry (GC-MS), and Herpai et al. [18] made a sensitive and rapid liquid chromatographic method for the determination of concentrations of high-fructose corn syrup in honey; however, these methods required specialty and cost equipment. As is show in Table 4, no exist statistic difference between a HPLC method and the polarimetric method here proposed, confirming that fructose-glucose ratio can be determined using a polarimetric method instead of the commonly used HPLC. Therefore, the method proposed in the present work reduced the time and equipment necessary for fructose-glucose ratio determination, making their quantitation faster and easier.

\section{Conclusion}

A fast and inexpensive analytical method to detect fructose-glucose ratio in agave syrup was developed. The polarimetric evaluation proposed to fructose-glucose ratio determination in agave syrup, could improve agave syrup factory process, due it is a rapid and economic way to fructose-glucose ratio detection.

\section{References}

1. Cozma A, Sievenpiper J, Chiavaroli L (2011) Effect of fructose on glycemic control in diabetes: A meta-analysis of controlled feeding trials. Can $J$ Diabetes 35: 420-421.

2. Foster-Powell K, Holt S, Brand-Miller J (2002) International table of glycemic index and glycemic load values. Am J Clin Nutr 76: 5-56.

3. Phillips K, Carlsen M, Blomhoff R (2009) Total antioxidant content of alternatives to refined sugar. J Am Diet Assoc 109: 64-71.

4. Davidson J, Ortiz B (1983) The bacterial properties of an Aztec wound remedy. J Ethnopharmacol 8: 149-161.

5. Silva A, Martinez K, Brito A, Giulietti M (2010) Separation of glucose and fructose by freezing crystallization. Cryst Res Technol 45: 1032-1034.

6. Justino L, Caldeira M, Gil V, Baptista M, Cunha A, et al. (1997) Determination of changes in sugar composition during the aging of honey by HPLC, FTIR and NMR spectroscopy. Carbohydr Polym 34: 435-450.

7. Cordella C, Moussa I, Martel A, Sbirrazzuoli N, Lizzani-Cuvelier L (2002) Recent developments in food characterization and adulteration detection: Techniqueoriented perspectives. J Agric Food Chem 50: 1751-1764.

8. Bogdanov S, Martin P, Lullmann C (1997) Determination of sugars by HPLC. Apidologie 1-59.

9. Barclaya T, Ginic-Markovica P, Cooper D, Petrovsky N (2011) The chemistry and sources of fructose and their effect on its utility and health implications. $J$ Excipient Food Chem 3: 67-82.

10. Batsoulis A, Siatis N, Kimbaris A, Alissandrakis E, Pappas C, et al. (2005) FTRaman spectroscopic simultaneous determination of fructose and glucose in honey. J Agric Food Chem 53: 207-210.

11. Astolfi $\mathrm{V}$, Joris $\mathrm{J}$, Verlindo R (2011) Operation of a fixed-bed bioreactor in batch and fed-batch modes for production of inulinase by solid-state fermentation. Biochem Eng J 59: 39-49.

12. Nava-Cruz N, Medina-Morales M, Martinez J, Rodriguez R, Aguilar C (2014) Agave biotechnology: An overview. Crit Rev Biotechnol 24: 1-14.

13. Li S, Zhang X, Shan Y, Su D, Ma Q, et al. (2016) Qualitative and quantitative detection of honey adulterated with high-fructose corn syrup and maltose syrup by using near-infrared spectroscopy. Food Chem 218:231-236.

14. Salah M, Eid A (2006) Chromatographic separation of fructose from date syrup. IJFANS 57: 83-96.

15. Ya-Jun W, Xia-Wei J, Zhi-Qiang L, Li-Qun J, Cheng-Jun L, et al. (2016) Isolation of fructose from high-fructose corn syrup with calcium immobilized strong acid cation exchanger: Isotherms, kinetics, and fixed-bed chromatography study. Can J Chem Eng 94: 537-546.

16. Cabañero A, Recio J, Rupérez M (2006) Liquid chromatography coupled to isotope ratio mass spectrometry: A new perspective on honey adulteration detection. J Agric Food Chem 54: 9719-9727.

17. Ruiz-Matute A, Weiss M, Sammataro D, Finely J, Sanz M (2010) Carbohydrate composition of high-fructose corn syrups (HFCS) used for bee feeding: Effect on honey composition. J Agric Food Chem 58: 7317-7322.

18. Herpai Z, Szigeti J, Csapó J (2013) A rapid and sensitive method for the determination of high-fructose corn syrup (HFCS) in honey. Acta Universitatis Sapientiae-Alimentaria 6: 5-13. 